\title{
Proceedings of the 15th conference of the International Work Group for Palaeoethnobotany, Wilhelmshaven 2010
}

\author{
Felix Bittmann
}

Received: 1 August 2011/Accepted: 2 August 2011/Published online: 11 August 2011

(C) Springer-Verlag 2011

The current issue contains a selection of articles originating from lectures given at the 15th conference of the IWGP, which took place at Wilhelmshaven, Germany, from May 31 st to June 6th, 2010. The conference was held on occasion of the 75th birthday of Prof. Karl-Ernst Behre in 2010, who was among the founders of the work group in 1968 and a participant of the meetings since then (Fig. 1). Furthermore Vegetation History and Archaeobotany, which was started by him, had its 20th anniversary this year. It has since become well established and leading in its field, comprising vegetation history as well as archaeobotany and related fields of palaeoecology. Therefore this issue is dedicated to him in recognition of his merits, not only for the work group, but for the whole field of vegetation history and also the journal for which he still plays a major role as Associate Editor.

Starting with the double issue vol. 5/1-2 of Vegetation History and Archaeobotany in 1996, this is now the 6th issue of this series (and part of the 20th anniversary volume). As at the previous meeting in Kraków in 2007, again more than 200 participants from 32 countries registered, giving evidence of the increasing importance of the work group in recent years (Fig. 2). Traditionally the organiser(s) of the conference edit the proceedings, supported by the Associate Editors with expertise in archaeobotany to deal with the large number of submissions within a reasonable time. Involved were: Corrie C. Bakels, Stefanie Jacomet, Małgorzata Latałowa, Marijke van der Veen,

Communicated by F. Bittmann.

F. Bittmann ( ()

Lower Saxony Institute for Historical Coastal Research,

Viktoriastr. 26/28, 26382 Wilhelmshaven, Germany

e-mail: bittmann@nihk.de
Andrew Fairbairn (partly), George Willcox and Felix Bittmann (Editor in Chief and editor of this issue who in addition made the final decisions, technical improvements, layout of figures and line-up of contributions). As usual, the editorial responsibility can be seen from each single article. Special thanks go to all colleagues involved in the peer reviewing. Without their help and their most valuable and critical reviews it would not have been possible to improve and to select contributions of high quality. They did a great job and are acknowledged at the end. Finally I

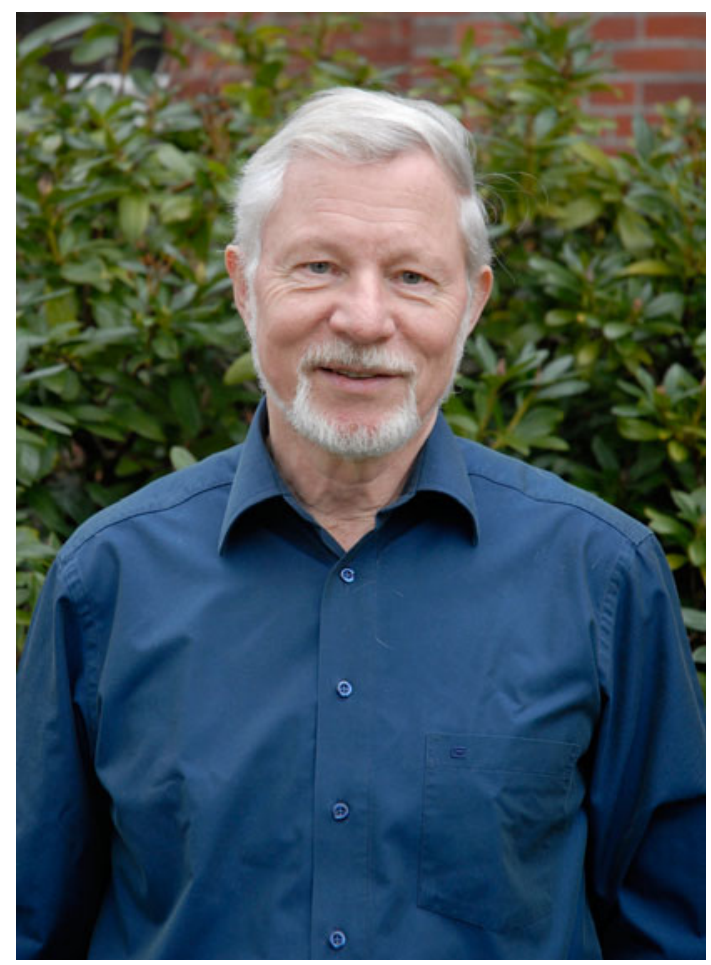

Fig. 1 Prof. Dr. Karl-Ernst Behre (Photo R. Kiepe, NIhK) 


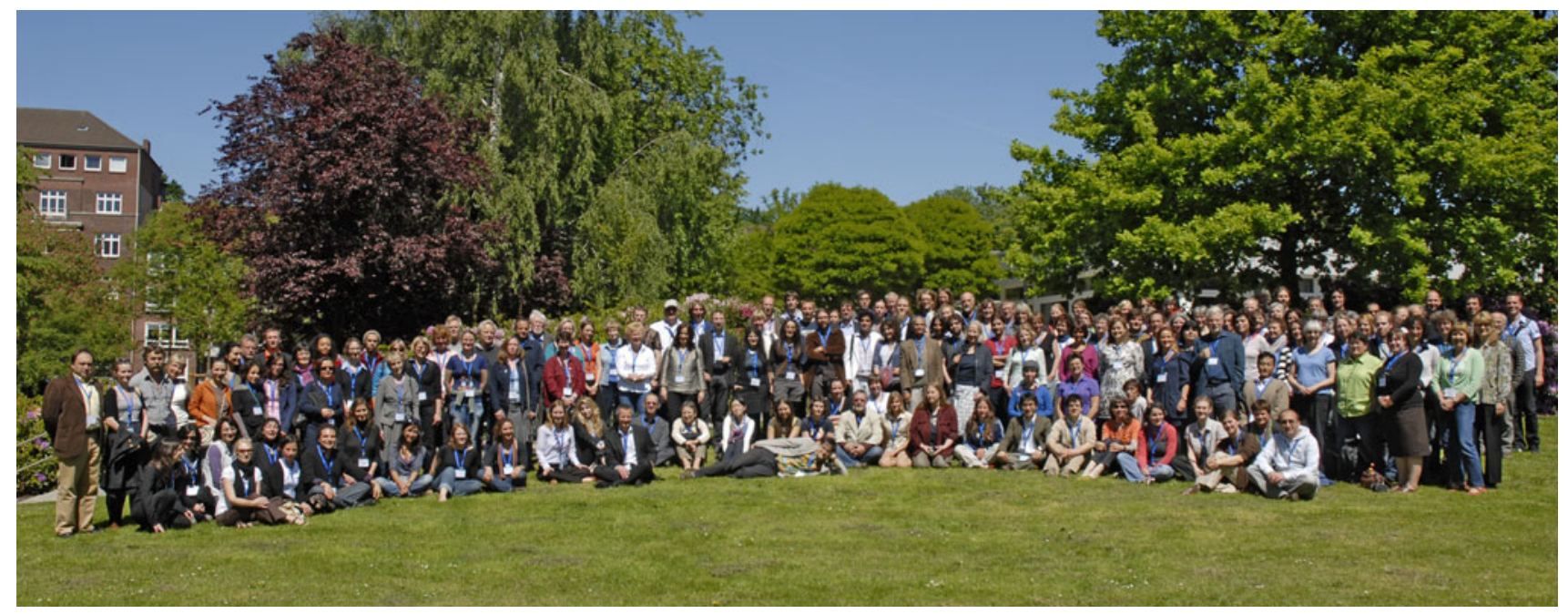

Fig. 2 Participants at the 15th IWGP conference, Wilhelmshaven June 3rd, 2010 (Photo R. Kiepe, NIhK)

have to thank our copy/language editors James Greig and John Daniell for their great work which is highly appreciated and an indispensable guarantee of a high standard beyond the scientific content.

Thanks to the generous financial support to this extended issue by Tamara Welschot (Springer) and the Marschenrat zur Förderung der Forschung im Küstengebiet der Nordsee e.V., the page surplus and free copies for the participants could be financed.

About 85 oral and 90 poster contributions, a collection of which can be visited and downloaded at the IWGP homepage (http://www.archaeobotany.org/posters.php) were presented during the conference. For the current issue 32 papers have been submitted, of which 14 made it through the reviewing procedure. They are arranged thematically starting with five original contributions dealing with European early to late Neolithic sites and topics. These are followed by three articles mainly on Roman sites in southern France, Morocco and Arabia. Three papers present morphological studies to enhance identification of remains and the last original contribution shows experimental results to trace olive processing in the archaeobotanical record. The issue is completed by two review articles on changes in cereal cultivation during the Iron Age in Sweden and on Roman cremations in northern Italy.

\section{Acknowledgement to referees}

Asouti, Eleni; Liverpool, UK

Bakels, Corrie C.; Leiden, NL*

Bittmann, Felix; Wilhelmshaven, D*

Bogaard, Amy; Nottingham, UK*

Bouby, Laurent; Montpellier, F

Brinkkemper, Otto; Amersfoort, NL
Chapman, John C; Durham, UK

Charles, Michael; Sheffield, UK

Clapham, Alan; Worcester, UK

Colledge, Sue; London, UK

Deckers, Katleen; Tübingen, D

Doppler, Thomas; Basel, CH

Jacomet, Stefanie; Basel, $\mathrm{CH}^{*}$

Jones, Glynis; Sheffield, UK

Kirleis, Wiebke; Kiel, D

Kislev, Mordechai; Ramat-Gan, IL

Kohler-Schneider, Marianne; Wien, A

Kreuz, Angela; Wiesbaden, D

Kubiak-Martens, Lucy; Zaandam, NL

Latałowa, Małgorzata; Gdańsk, $\mathrm{Pl}^{*}$

Livarda, Alexandra; Oxford, UK

Marinova, Elena; Leuven, B

Martin, Lucie; Paris, F

Miller, Naomi; Philadelphia, USA

Mitka, Jozef; Kraków, PL

Nesbitt, Mark; London, UK

Out, Welmoed; Barcelona, E

Palmer, Carol; Amman, JOR

Samuel, Delwen; London, UK

Schaminée, J.H.J. (Joop); Wageningen, NL

Van der Veen, Marijke; Leicester, UK*

Van Haaster, Henk; Zaandam, NL

Van Tongeren, Onno; Arnhem, NL

Viklund, Karin; Umeå, S

Voltas Velasco, Jordi; Lleida, E

Wiethold, Julian; Metz, F

Willcox, George; St-Paul-le-Jeune, F*

Zech-Matterne, Veronique; Paris, $F^{*}$

*Multiple reviews 